\title{
TI.9.5
}

\section{eduPerson Object Class Specification (200712)}

- PDF: 00007-eduPersonObjectClassSpecification200712.pdf

- HTML: internet2-mace-dir-eduperson-200712.html

\section{More Information}

\begin{tabular}{|l|l|}
\hline Repository ID & TI.9.5 \\
\hline Persistent URL & http://doi.org/10.26869/TI.9.5 \\
\hline Title & eduPerson Object Class Specification (200712) \\
\hline Authors & MACE-Dir \\
\hline Sponsor & MACE \\
\hline Review & \\
\hline Status & Legacy \\
\hline Publish Date & April 14, 2006; amended December 12, 2007 \\
\hline DOI & $10.26869 /$ TI.9.5 \\
\hline Signature & \\
\hline Deprecated & Yes \\
\hline Future Review & \\
\hline Supersedes & TI.9.4 \\
\hline Format & PDF \\
\hline Related Docs & \\
\hline Development Location & \\
\hline IP Framework & \\
\hline Subject Tags & middlewarerescue \\
\hline Notes & \\
\hline & \\
\hline
\end{tabular}

